\title{
openheart Atrial arrhythmias and thromboembolic complications in adults post Fontan surgery
}

Darryl Wan (D) , Jasmine Grewal, Amanda Barlow, Marla Kiess, Derek Human, Andrew D Krahn, Mounir Riahi, Santabhanu Chakrabarti

To cite: Wan D, Grewal J, Barlow A, et al. Atrial arrhythmias and thromboembolic complications in adults post Fontan surgery. Open Heart 2020;7:e001224. doi:10.1136/

openhrt-2019-001224

Received 12 December 2019 Revised 29 July 2020 Accepted 2 September 2020

A Check for updates

(C) Author(s) (or their employer(s)) 2020. Re-use permitted under CC BY-NC. No commercial re-use. See rights and permissions. Published by BMJ.

Department of Medicine, Division of Cardiology, University of British Columbia, Vancouver, British Columbia, Canada

Correspondence to Dr Santabhanu Chakrabarti; schakrabarti@providencehealth. bc.ca

\section{ABSTRACT}

Objective Patients with Fontan surgery experience late complications in adulthood. We studied the factors associated with the development and maintenance of atrial arrhythmias and thromboembolic complications in an adult population with univentricuar physiology post Fontan surgery.

Methods Single centre retrospective cohort study of patients $\geq 18$ years of age with Fontan circulation followed at our quaternary care centre for more than 1 year were included. Univariate and multivariate regression models were used where applicable to ascertain clinically significant associations between risk factors and complications.

Results 93 patients were included (age $30.2 \pm 8.8$ years, 58\% men). 28 (30\%) had atriopulmonary Fontan connection, 35 (37.6\%) had lateral tunnel Fontan and 29 (31.1\%) had extracardiac Fontan pathway. After a mean of $7.27 \pm 5.1$ years, atrial arrhythmia was noted in 37 patients (39.8\%), of which 13 developed had atrial fibrillation (14\%). The presence of atrial arrhythmia was associated with the number of prior cardiac surgeries/ procedures, increasing age and prior atriopulmonary Fontan operation. Thromboembolic events were present in 31 patients (33\%); among them 14 had stroke (45\%), 3 had transient ischaemic attack (9.7\%), 7 had pulmonary embolism (22.6\%) and 5 had atrial thrombus with imaging (16.1\%). The presence of thromboembolic events was only associated with age and the presence of cirrhosis in multivariate analysis.

Conclusions Atrial arrhythmias are common in adults with Fontan circulation at an early age, and are associated with prior surgical history and increasing age. Traditional risk factors may not be associated with atrial arrhythmia or thromboembolism in this cohort.

\section{INTRODUCTION}

The Fontan procedure was first described in 1971 independently by Drs Fontan and Kreutzer. ${ }^{12}$ It has since been used as a palliative procedure for children born with univentricular congenital heart disease. Since its inception, several modifications have been made, leading to three general variations in contemporary practice: atriopulmonary

\section{Key questions}

What is already known about this subject?

- Adults with congenital heart disease are known to suffer late complications including arrhythmia and thromboembolic events. However, the population is highly variable depending on underlying pathology and surgical correction. The rate of atrial arrhythmia and thromboembolic complications in adult patients with Fontan circulation is poorly described.

What does this study add?

- This study adds to a small body of literature that describes the late complications in adult patients with Fontan physiology. The risk of atrial arrhythmia and thromboembolism are described in a cohort of patients with medium-term follow-up duration.

How might this impact on clinical practice?

- Understanding the rate of atrial arrhythmia and associated thromboembolic events may help clinicians tailor screening and therapeutic strategies to prevent late complications, thereby reducing overall morbidity and mortality.

connection, intracardiac lateral tunnel connection and extracardiac connection. ${ }^{3}$

While the procedure significantly improved survival during early infancy, a variety of extracardiac and cardiac complications including Fontan circuit failure are observed in medium to long-term follow-up. The failure of a Fontan circuit is a harbinger for arrhythmic and thromboembolic (TE) complications, both of which contribute to a significant burden of morbidity and mortality. ${ }^{4-8}$ However, the types of atrial arrhythmias affecting adults with congenital heart disease (ACHD) are poorly understood, and data describing risk factors associated with atrial arrhythmia are scarce. ${ }^{9-11}$ Similarly, thromboembolic complications in adults with Fontan circulation from atrial arrhythmias are poorly described and there remains a paucity of tools to predict thromboembolism. ${ }^{12}$ 
We performed a cohort study to understand the clinical characteristics and natural history of adult patients with Fontan circulation followed at our centre. We describe the risk factors associated with atrial arrhythmia and thromboembolism in adults with repaired univentricular congenital heart disease with Fontan procedure. We hypothesised that patients with Fontan physiology would have high rates of atrial arrhythmia and thromboembolism.

\section{METHODS}

We performed a retrospective chart review of all patients who had been followed by our ACHD clinic from November 1997 to November 2017 at St Paul's Hospital in Vancouver, Canada, to identify eligible patients for this study. St Paul's Hospital is the single referral centre for adult congenital heart disease in the province of British Columbia. Patients who were $\geq 18$ years of age with a previously palliative Fontan operation were included in this study. Patients with $<1$-year follow-up were excluded.

Data was collected regarding demographic information, underlying diagnoses, comorbidities, arrhythmic details, thromboembolic details and medications at most recent contact. As many patients were transitioned from paediatric care to our ACHD clinic, the follow-up period was calculated by the difference between first intake visit at our clinic, and the most recent follow-up date. Age was defined as the age at last ACHD clinic contact. All arrhythmic diagnoses were confirmed by 12-lead surface electrocardiography or 24-hour Holter monitoring, and verified by certified cardiologists. The duration of arrhythmic diagnoses were obtained as much as possible from retrospective review. Thromboembolic phenomena were confirmed by imaging modalities including echocardiography, CT and ultrasonography. The presence of thromboembolism was confirmed by qualified congenital echocardiographers and radiologists, depending on the specified modality. The number of cardiac surgeries/ procedures was defined as the total number of cardiac surgeries or catheter-based procedures leading to intervention. Diagnostic studies were not included. Procedures that did not involve direct cardiac tissue manipulation were not included.

Statistical analysis was performed with standard statistical software including Microsoft Excel and IBM SPSS Statistics software. Mean values were calculated for continuous variables and reported with the associated SD. Fisher's exact test was used to compare categorical values, and a Student's t-test was used to compare categorical and continuous variables. A logistic regression model was used to compare risk factors to outcomes, and a multivariate regression model was used where several predictors were hypothesised to influence outcome.

\section{RESULTS}

A total of 126 patients were identified as potentially eligible for this study by diagnostic coding reference. Ninety-three
Table 1 Baseline demographic and clinical characteristics

\begin{tabular}{|c|c|}
\hline Demographic & Value \\
\hline Male $(n,(\%))$ & $54,(58 \%)$ \\
\hline Age (years) & $30.2 \pm 8.8$ \\
\hline ACHD follow-up (years) & $7.27 \pm 5.1$ \\
\hline Total follow-up (years) & 2809 \\
\hline Average cardiac surgeries/procedures & $4.07 \pm 1.59$ \\
\hline \multicolumn{2}{|l|}{ Clinical characteristic, n (\%) } \\
\hline \multicolumn{2}{|l|}{ Fontan type } \\
\hline Atriopulmonary & $28(30.1)$ \\
\hline Lateral tunnel & $35(37.6)$ \\
\hline Extracardiac & $29(31.1)$ \\
\hline \multicolumn{2}{|l|}{ AV regurgitation } \\
\hline None/trivial & $41(44.1)$ \\
\hline Mild & $31(33.3)$ \\
\hline Moderate & $16(17.2)$ \\
\hline Severe & $2(2.2)$ \\
\hline \multicolumn{2}{|l|}{ Systemic ventricle } \\
\hline LV & $69(74.2)$ \\
\hline RV & $21(22.6)$ \\
\hline \multicolumn{2}{|l|}{ Systolic dysfunction } \\
\hline None & $50(53.8)$ \\
\hline Mild & $31(33.3)$ \\
\hline Moderate & $9(9.7)$ \\
\hline Severe & $1(1.1)$ \\
\hline \multicolumn{2}{|l|}{ Medication, n (\%) } \\
\hline ASA & $27(29.0)$ \\
\hline Warfarin & 49 (52.7) \\
\hline DOAC & $3(3.2)$ \\
\hline LMWH & $2(2.2)$ \\
\hline ACEi & $33(35.5)$ \\
\hline $\mathrm{BB}$ & $29(31.2)$ \\
\hline Digoxin & $11(11.8)$ \\
\hline Diuretic & $16(17.2)$ \\
\hline Amiodarone & $5(5.4)$ \\
\hline Sotalol & $8(8.6)$ \\
\hline
\end{tabular}

ACEi, angiotensin converting enzyme inhibitor; ASA, acetylsalicylic acid; AV, atrioventricular; BB, beta blocker; DOAC, direct oral anticoagulant; LMWH, low molecular weight heparin; LV, left ventricle; RV, right ventricle.

patients met final inclusion criteria for this study, of which $54(58.1 \%)$ were men with a mean age of 30.2 SD 8.8 years (tables 1 and 2). The majority of patients $(\mathrm{n}=35,37.6 \%)$ had a lateral tunnel connection, whereas $29(31.2 \%)$ had an extracardiac connection, with the remainder $(n=28$, $30.1 \%$ ) having an atriopulmonary connection. The mean age at the time of Fontan completion was 7.9 years.

\section{Atrial arrhythmia}

The presence of atrial arrhythmia was significant in this population, with 37 (39.8\%) patients having a documented 


\begin{tabular}{|c|c|c|c|}
\hline $\begin{array}{l}\begin{array}{l}\text { Age } \\
\text { range }\end{array} \\
\end{array}$ & Fontan type & Follow-up & $\begin{array}{l}\text { Cirrhosis } \\
\text { present }\end{array}$ \\
\hline$<30$ & $\begin{array}{l}\text { Classic }=7 \\
\text { Lateral }=18 \\
\text { Extra-cardiac }=25 \\
\text { Unknown }=1\end{array}$ & $4.0 \pm 2.4$ years & 3 \\
\hline $30-40$ & $\begin{array}{l}\text { classic }=13 \\
\text { Lateral }=14 \\
\text { Extra-cardiac }=1\end{array}$ & $11.6 \pm 4.4$ years & 3 \\
\hline $40-50$ & $\begin{array}{l}\text { Classic }=5 \\
\text { Lateral }=0 \\
\text { Extra-cardiac }=1\end{array}$ & $11.5 \pm 5.8$ years & 2 \\
\hline$\geq 50$ & $\begin{array}{l}\text { Classic }=3 \\
\text { Lateral }=2 \\
\text { Extra-cardiac }=1\end{array}$ & $11.0 \pm 4.8$ years & 1 \\
\hline
\end{tabular}

$\mathrm{ACHD}$, adults with congenital heart disease; DOAC, direct oral anticoagulant.

history of some type of atrial arrhythmia during their lifetime (table 3). The most common recorded arrhythmias were atrial fibrillation $(n=13,14.0 \%)$, atrial flutter $(n=16$, $17.2 \%)$ and ectopic atrial tachycardia $(\mathrm{n}=16,17.2 \%)$.

In multivariate regression, age was significantly associated with the presence of any atrial arrhythmia (OR 1.10; 95\% CI (1.03 to 1.18)). A history of an atriopulmonary Fontan connection (OR 5.77; 95\% CI (1.80 to 18.48)) and the total number of lifetime cardiac surgeries or procedures (OR 1.50; 95\% CI (1.06 to 2.12)) were significant predictors of a composite of atrial arrhythmias.

\begin{tabular}{|c|c|}
\hline & N (\%) \\
\hline \multicolumn{2}{|l|}{ Atrial arrhythmia } \\
\hline AF & $13(14.0)$ \\
\hline AFL & $16(17.2)$ \\
\hline EAT & $16(17.2)$ \\
\hline Other & $1(1.1)$ \\
\hline No $A A$ & $56(60.2)$ \\
\hline Ablation & $5(5.4)$ \\
\hline DCCV & $11(11.8)$ \\
\hline \multicolumn{2}{|c|}{ Thromboembolism } \\
\hline CVA & $14(15.1)$ \\
\hline TIA & $3(3.2)$ \\
\hline $\mathrm{PE}$ & $7(7.5)$ \\
\hline DVT & $4(4.3)$ \\
\hline RA thrombus & $4(4.3)$ \\
\hline Other & $8(8.6)$ \\
\hline No TE & $62(66.7)$ \\
\hline
\end{tabular}

$A A$, atrial arrhythmia; $A F$, atrial fibrillation; $A F L$, atrial flutter; CVA, cerebrovascular accident; DCCV, direct current cardioversion; DVT, deep venous thrombosis; EAT, ectopic atrial tachycardia; PE, pulmonary embolism; RA, right atrial; TE, thromboembolism; TIA, transient ischaemic attack.
The degree of atrioventricular valve regurgitation was not associated with the presence of atrial arrhythmia (table 4).

There were relatively few events of traditional metabolic risk factors such as recorded systemic hypertension or diabetes mellitus in this study, resulting in insufficient data for robust multivariate analysis.

\section{Thromboembolism}

A total of 41 life-time thromboembolic events were recorded in our population, occurring in 31 patients $(33.3 \%)$. This accounted for an annual thromboembolic event rate of $1.46 \%$. The majority of these events $(\mathrm{n}=17,41.5 \%)$ were cerebrovascular accidents (CVA) or transient ischaemic attacks (TIA). Other thromboembolic events included pulmonary embolism, deep venous thrombosis and right atrial thrombus (table 2).

In multivariate regression, a history of cirrhosis was predictive of the presence of any thromboembolic event (OR 6.28; CI (1.27 to 31.05)). Age was also associated with thromboembolism (OR 1.06; 95\% CI (1.00 to 1.13)), but the presence of atrial arrhythmia was not (OR 0.41; 95\% CI (0.13 to 1.37 ) (tables 5 and 6 ).

In subgroup analysis of patients with a history of CVA or TIA, the presence of congestive heart failure (CHF) was significantly associated with having CVA/TIA (OR $12.47 ; 95 \%$ CI (1.37 to 113.94$))$ table 7 . The impact of anticoagulation and antiplatelet therapy as thromboembolic prophylaxis could not be captured in this multivariate regression model due to a lack of data regarding temporal prescription practices.

\section{Anticoagulation}

In the subgroup of patients with thromboembolism, there was a variety of anticoagulation practices at the time of thromboembolism. Due to the retrospective nature of this study, and the reality that many events were quite remote, data was incomplete and the anticoagulation status was not available for $18(45 \%)$ patients. Nine out of 40 events $(22.5 \%)$ occurred while patients were on therapeutic anticoagulation with warfarin. No patients were on direct oral anticoagulants at the time of thromboembolism table 7 .

\section{DISCUSSION}

This study describes our experience reporting late complications of an adult population with repaired univentricular circulation. Unlike previous studies that describe arrhythmic and thromboembolic complications in the perioperative and early postoperative periods, our study reflects a population of patients with Fontan physiology who have survived to adulthood. These patients become susceptible to the consequences of abnormal haemodynamics, leading to arrhythmic and thromboembolic complications as the Fontan circuit fails.

The adult population described in this study is a relatively young cohort (mean age $30.2 \pm 8.8$ years) with a lifetime follow-up of 2809 patient-years. The prevalence of atrial 
Table 4 Risk factors associated with having any atrial arrhythmia

\begin{tabular}{llcll}
\hline Characteristic & Univariate $(95 \% \mathrm{Cl})$ & P value & Multivariate $(\mathbf{9 5 \%} \mathbf{C l})$ & P value \\
\hline Atriopulmonary Fontan & $\mathbf{6 . 9 1}(\mathbf{2 . 5 7}$ to $\mathbf{1 8 . 6 0})$ & $<\mathbf{0 . 0 0 1}$ & $\mathbf{5 . 7 7}(\mathbf{1 . 8 0}$ to 18.48$)$ & $\mathbf{0 . 0 0 3}$ \\
\hline Age & $\mathbf{1 . 1 2}(\mathbf{1 . 0 5}$ to 1.19$)$ & $\mathbf{0 . 0 0 1}$ & $\mathbf{1 . 1 0}(\mathbf{1 . 0 3}$ to $\mathbf{1 . 1 8})$ & $\mathbf{0 . 0 0 6}$ \\
Number of cardiac surgeries/procedures & $1.22(0.93$ to 1.61$)$ & 0.15 & $\mathbf{1 . 5 0}(\mathbf{1 . 0 6}$ to 2.12$)$ & $\mathbf{0 . 0 2 1}$ \\
Cirrhosis & $\mathbf{6 . 1 8}(\mathbf{1 . 2 1}$ to $\mathbf{3 1 . 6 9})$ & 0.03 & $6.90(0.96$ to 49.60$)$ & 0.06 \\
\hline
\end{tabular}

\begin{tabular}{|c|c|c|c|}
\hline Characteristic & $\begin{array}{l}\text { Univariate } \\
(95 \% \mathrm{Cl})\end{array}$ & $\begin{array}{l}\text { Multivariate } \\
(95 \% \mathrm{Cl})\end{array}$ & $P$ value \\
\hline Age & 1.05 (1.00 to 1.11$)$ & 1.06 (1.00 to 1.12$)$ & 0.05 \\
\hline Cirrhosis & $5.22(1.20$ to 22.62$)$ & 5.44 (1.13 to 26.21$)$ & 0.04 \\
\hline Any AA & 1.32 (0.54 to 3.22$)$ & 0.65 (0.22 to 1.93$)$ & 0.44 \\
\hline
\end{tabular}

$\mathrm{AA}$, atrial arrhythmia.

Table 6 Risk factors associated with history of CVA/TIA

\begin{tabular}{ll}
\hline Characteristic & Univariate $(95 \% \mathbf{C l})$ \\
\hline Age & $1.03(0.98$ to 1.10$)$ \\
Number of cardiac surgeries/procedures & $1.19(0.85$ to 1.67$)$ \\
CHF & $\mathbf{8 . 5 4}(\mathbf{1 . 3 0}$ to 56.17$)$ \\
AF & $1.52(0.37$ to 6.31$)$ \\
\hline
\end{tabular}

$\mathrm{AF}$, atrial fibrillation; CHF, congestive heart failure; CVA, cerebrovascular accident; TIA, transient ischaemic attack.

Table 7 Anticoagulation status of patients at the time of thromboembolism

\begin{tabular}{lc}
\hline Anticoagulation status & $\mathbf{n = 4 0}$ \\
\hline None & $5(12.5 \%)$ \\
ASA only & $8(20 \%)$ \\
Warfarin only & $7(17.5 \%)$ \\
ASA + warfarin & $2(5 \%)$ \\
Unknown & $18(45 \%)$ \\
\hline
\end{tabular}

ASA, acetylsalicyclic acid.

arrhythmia in this young population was high at $39.8 \%$. This is significantly higher than prior studies in paediatric populations describing atrial arrhythmic rates of $4 \%$ to $17 \% .^{11} 1314$ While atrial arrhythmia does not portend the same mortality as ventricular arrhythmias, these events still lead to significant morbidity and mortality due to associated complications such as systemic thromboembolism. In addition, patients with Fontan circulation are inherently at an increased risk of thromboembolic complications due to the lack of a subpulmonic pump. As a result, the addition of atrial arrhythmia as an additional risk factor may significantly exacerbate thromboembolic risk.

Our study also demonstrates that cardiovascular surgeries and procedures act as a significant risk factor for the development of atrial arrhythmia. The presence of an atriopulmonary connection was associated with an increased risk of developing atrial arrhythmia. We hypothesise that this may be due to the burden of atrial scar produced by surgical manipulation of the right atrium itself. In addition, the total lifetime number of cardiac surgeries or interventional procedures was also associated with the development of atrial arrhythmia. This may be attributable to increased scar burden as a result of multiple intracardiac procedures.

One-third of the patients in our study cohort experienced a thromboembolic event. This is a significant thromboembolic event rate given the young age of this cohort, and somewhat higher than previous studies reporting thromboembolic rates of $0 \%$ to $20 \%{ }^{6}$ It should however be noted that this figure represents the total thromboembolic rate, as it was difficult to discern the effect of anticoagulation and antiplatelet therapy in this retrospective study. Given these limitations, the only significant predictors for a composite of thromboembolic events were age and the presence of cirrhosis by CT imaging or abdominal ultrasonography. However, this should be interpreted cautiously as the diagnosis of cirrhosis is definitively achieved by tissue biopsy, which was not available for most patients.

Interestingly, the presence of atrial arrhythmia was not a significant predictor of thromboembolism in this group. From population-based studies, we know that the presence of atrial arrhythmia is a predictor of systemic thromboembolism, and in fact is the rationale behind prophylaxis with antithrombotic therapy. ${ }^{15-17}$ Our analysis was somewhat discordant, which may be reflective of a small sample size. One potential risk factor identified in this study is the presence of cirrhosis. Cirrhosis and Fontan-associated liver disease are late complications of a Fontan circulation. The association with thromboembolism may be explained by concomitant Fontan circuit failure leading to stasis and increased Fontan circuit pressures. An alternative explanation may be the coagulopathy that is well-recognised in patients with cirrhosis. The relationship between cirrhosis and stroke has been previously described in the general population, ${ }^{18}$ and a similar relationship may be present in Fontan patients. The combination of these factors may lead to an increased thromboembolic potential.

Our analysis also suggests an association between $\mathrm{CHF}$ and CVA/TIA. While this was significant in multivariable modelling, the finding should be interpreted with caution due to the small number of patients in this subgroup. The definition of CHF in this study was based on clinical diagnostic codes, rather than robust quantitative criteria. However, a relationship between heart failure and CVA/TIA could 
be plausible in this population with structurally abnormal hearts where increasing Fontan circuit pressures may lead to vascular endothelial dysfunction and increased thromboembolic potential.

We therefore suspect that our multivariate model was unable to capture other risk factors that affect thromboembolic risk. This may be at least partially explained by the presence of antiplatelet or anticoagulant therapy. Due to the nature of our retrospective study, we were unable to determine the status, adherence or compliance of antithrombotic medications surrounding events. In our centre, patients are closely followed by specialists in dedicated adult congenital heart disease. If patients at high risk of developing thromboembolism—such as patients with atrial arrhythmia—were appropriately identified and treated with prophylaxis, perhaps this would account for a lower risk of thromboembolism in this population. Similarly, our study was unable to capture the effect of fenestration and fenestration closure in this population.

\section{LIMITATIONS}

We recognise that our study has several inherent limitations. This is a single centre study describing our experience, and the specific findings may not be generalisable to the greater ACHD population. The nature of a retrospective observational study introduces multiple confounders that may affect the validity and reproducibility of this study. In addition, we did not have access to arrhythmic data from intracardiac devices, which may affect the completeness of data collected. However, the data obtained over 2809 patient-years of follow-up has provided meaningful insight into the natural history of this abnormal haemodynamic physiology. Further, as our understanding of adult congenital heart disease continues to evolve, so do treatment guidelines which may explain some of the variability in data, outcomes and management. Finally, it should be noted that these data only reflects the cohort of patients who have survived long enough to be followed at an adult congenital heart disease clinic. Many patients with Fontan circulation do not survive to adulthood and this study cannot be generalised to younger patients.

\section{CONCLUSIONS}

Adult patients with Fontan circulation have a high risk of arrhythmic and thromboembolic complications. The development of atrial arrhythmias may be associated with cardiovascular surgical history, advancing age and the presence of cirrhosis. There may also be a relationship between the presence of hepatic dysfunction and systemic thromboembolism. However, these findings need to be confirmed in larger cohorts.

Contributors This author takes responsibility for all aspects of the reliability and freedom from bias of the data presented and their discussed interpretation.

Funding The authors have not declared a specific grant for this research from any funding agency in the public, commercial or not-for-profit sectors.
Competing interests None declared.

Patient consent for publication Not required.

Ethics approval Approval from institutional Research Ethics Board (REB) was obtained prior to initiation of this study.

Provenance and peer review Not commissioned; externally peer reviewed.

Data availability statement Data is not in a repository but is available upon request from the corresponding author.

Open access This is an open access article distributed in accordance with the Creative Commons Attribution Non Commercial (CC BY-NC 4.0) license, which permits others to distribute, remix, adapt, build upon this work non-commercially, and license their derivative works on different terms, provided the original work is properly cited, appropriate credit is given, any changes made indicated, and the use is non-commercial. See: http://creativecommons.org/licenses/by-nc/4.0/.

ORCID iD

Darryl Wan http://orcid.org/0000-0002-1600-9478

\section{REFERENCES}

1 Fontan F, Baudet E. Surgical repair of tricuspid atresia. Thorax 1971;26:240-8.

2 Kreutzer G, Galíndez E, Bono H, et al. An operation for the correction of tricuspid atresia. J Thorac Cardiovasc Surg 1973;66:613-21.

3 Davies RR, Chen JM, Mosca RS. The Fontan procedure: evolution in technique; attendant imperfections and transplantation for "failure". Semin Thorac Cardiovasc Surg Pediatr Card Surg Annu 2011;14:55-66.

4 Driscoll DJ, Offord KP, Feldt RH, et al. Five- to Fifteen-Year follow-up after Fontan operation, 1985.

5 Kim S-J, Kim W-H, Lim H-G, et al. Outcome of 200 patients after an extracardiac Fontan procedure. J Thorac Cardiovasc Surg 2008;136:108-16.

6 Monagle P, Karl TR. Thromboembolic problems after the Fontan operation. Semin Thorac Cardiovasc Surg Pediatr Card Surg Annu 2002;5:36-47.

7 Tweddell JS, Nersesian M, Mussatto KA, et al. Fontan palliation in the modern era: factors impacting mortality and morbidity. Ann Thorac Surg 2009;88:1291-9.

8 Khairy P, Fernandes SM, Mayer JE, et al. Long-term survival, modes of death, and predictors of mortality in patients with Fontan surgery. Circulation 2008;117:85-92.

9 Shirai LK, Rosenthal DN, Reitz BA, et al. Arrhythmias and thromboembolic complications after the extracardiac Fontan operation. J Thorac Cardiovasc Surg 1998;115:499-505.

10 Gewillig M, Wyse RK, de Leval MR, et al. Early and late arrhythmias after the Fontan operation: predisposing factors and clinical consequences. Br Heart J 1992;67:72-9.

11 Lasa JJ, Glatz AC, Daga A, et al. Prevalence of arrhythmias late after the Fontan operation. Am J Cardiol 2014;113:1184-8.

12 McCrindle BW, Manlhiot C, Cochrane A, et al. Factors associated with thrombotic complications after the Fontan procedure: a secondary analysis of a multicenter, randomized trial of primary thromboprophylaxis for 2 years after the Fontan procedure. J Am Coll Cardiol 2013;61:346-53.

13 Stephenson EA, Lu M, Berul Cl, et al. Arrhythmias in a contemporary Fontan cohort: prevalence and clinical associations in a multicenter cross-sectional study. J Am Coll Cardiol 2010;56:890-6.

14 Durongpisitkul K, Porter CJ, Cetta F, et al. Predictors of early- and late-onset supraventricular tachyarrhythmias after Fontan operation. Circulation 1998;98:1099-107.

15 Cooper NJ, Sutton AJ, Lu G, et al. Mixed comparison of stroke prevention treatments in individuals with nonrheumatic atrial fibrillation. Arch Intern Med 2006;166:1269-75.

16 van Walraven C, Hart RG, Singer DE, et al. Oral anticoagulants vs aspirin in nonvalvular atrial fibrillation. JAMA 2002;288:2441.

17 Hart RG, Pearce LA, Aguilar MI. Meta-analysis: antithrombotic therapy to prevent stroke in patients who have nonvalvular atrial fibrillation. Ann Intern Med 2007;146:857-67.

18 Parikh NS, Navi BB, Schneider Y, et al. Association between cirrhosis and stroke in a nationally representative cohort. JAMA Neurol 2017;74:927-32. 